\title{
A CULTURA DO CUIDADO COMO EXCLUDENTE DA RELAÇÃO DE TRABALHO
}

\author{
THE CULTURE OF CARE AS AN EXCLUSIONARY ASPECT OF THE EMPLOYMENT \\ RELATIONSHIP
}

\author{
Juliana Teixeira Esteves ${ }^{1}$ \\ Faculdade de Direito de Recife (UFPE) \\ Tieta Tenório de Andrade Bitu ${ }^{2}$ \\ Faculdade Professor Dirson Maciel de Barros (FADIMAB) \\ Vitor Gomes Dantas Gurgel ${ }^{3}$ \\ Faculdade de Direito de Recife (UFPE)
}

\begin{abstract}
Resumo:
O texto desenvolve-se nas imbricações entre trabalho e gênero no contexto da sociedade patriarcal que insiste em manter, embora não revele, a desvalorização das profissões do cuidado (care). Através de pesquisa documental e análise qualitativa, partindo-se do reconhecimento da fundamentalidade do trabalho do cuidado, objetiva-se questionar a invisibilidade do trabalho feminino e a sua regulamentação em tempos de avanços tecnológicos capazes de mitigar o esforço e obliterar obrigações impostas ocultadas nas relações de trabalho entre os gêneros. Partiu-se da hipótese de que o direito tal como posto hoje é insuficiente na proteção do trabalho de cuidados e, analisando casos concretos, bem como por meio de uma pesquisa bibliográfica, reconheceu-se a necessidade de absorção das propostas feministas para criar uma alternativa à estrutura patriarcal que perpetua a desigualdade socioeconômica que aqui se comprovou ser recepcionada pelo direito.
\end{abstract}

Palavras-chave:

Trabalho do cuidado. Patriarcado. Feminismo.

\begin{abstract}
:
This paper discusses the internal relationships between work and gender in the context of a patriarchal society that insists on maintaining, though not revealing, the devaluation of caring professions. Through documental research and qualitative analysis, and based on the recognition of the fundamental nature of care, it aims to question the invisibility of women's labour and its regulation in times that technological advances are already capable of reducing work effort and obliterating imposed obligations hidden in the labour relations between genders. We started from the hypothesis that the law as it stands today is insufficient to protect the care work and, analyzing specific cases, as well as through a bibliographic research, the need to absorb feminist proposals has been recognized, in order to create an alternative to the patriarchal structure that perpetuates socio-economic inequality, which here has proven to be accepted by the law.
\end{abstract}

Keywords:

Care. Patriarchy. Feminism.

\footnotetext{
${ }^{1}$ Professora de Direito na Faculdade de Direito do Recife/UFPE. PhD em Economia política no IRES/FRANCE. Integrante da Academia Pernambucana de Direito do Trabalho, Pesquisadora da Rede Nacional de Pesquisas e Estudos em Direito do Trabalho e Seguridade Social e líder do Grupo de Pesquisa/CNPQ Direito, Economia e Política.

${ }^{2}$ Doutoranda e Mestra em Direito do Trabalho e Teoria Social Crítica pela Universidade Federal de Pernambuco. Professora da Faculdade Professor Dirson Maciel de Barros - FADIMAB. Advogada. Integrante da Academia Pernambucana de Direito do Trabalho, Pesquisadora da Rede Nacional de Pesquisas e Estudos em Direito do Trabalho e Seguridade Social e do Grupo de Pesquisa/CNPQ Direito, Economia e Política.

${ }^{3}$ Mestrando em Direito pela Universidade Federal de Pernambuco na linha de Direito do Trabalho e Teoria Social Crítica. Bolsista da Fundação de Amparo à Ciência e Tecnologia do Estado de Pernambuco. Integrante do Grupo de Pesquisa/CNPQ Direito, Economia e Política, ligado à Rede Nacional de Pesquisas e Estudos em Direito do Trabalho e Seguridade Social. Advogado.
} 


\section{INTRODUÇÃO}

Desde os sonhados autômatos no século XIX, e robôs da obra teatral R.U.R (1920) do dramaturgo tcheco Karel Čapek, em que autômatos com forma humana eram capazes de fazer tudo em lugar do homem, aportando na era da digitalização, as relações trabalho sofreram inúmeras metamorfoses, quase sempre sob a promessa de melhoria da qualidade de vida das pessoas. Mas, apesar de toda a reorganização da estrutura capitalista ${ }^{4}$ empresarial para automatizar a produção e flexibilizar a legislação a fim de majorar a extração da mais valia do exército reserva de mão-de-obra, a estrutura patriarcal ${ }^{5}$ de não-remuneração do trabalho doméstico-familiar persiste e com respaldo do judiciário.

O relatório OXFAM Tempo de cuidar: o trabalho de cuidado não remunerado e mal pago e a crise global da desigualdade" denuncia o lucro de 10,8 trilhões de dólares obtidos (ou o gasto subtraído) pelo trabalho de 12.5 bilhões de horas laboradas diariamente por mulheres e crianças ao redor do mundo. O valor supera em mais de três vezes o valor da indústria de tecnologia no mundo, perpetua a desigualdade social, viola a Agenda 2030 da $\mathrm{ONU}^{6}$ e até mesmo opiniões do Pontífice Papa Francisco (2020).

O tema do "trabalho gratuito" é apresentado ao mundo atual desde as primeiras reflexões sobre o trabalho na Internet. Tiziana Terranova (2000) reflete sobre o termo free labor. O artigo é escrito em inglês e insiste no duplo sentido de "free" no termo "free labor": pode significar "livre" e, portanto, opor-se ao trabalho forçado, mas também "gratuito" no sentido de não remunerado. Muitas pesquisas questionam a gratuidade do trabalho gerado nas mídias eletrônicas, por exemplo, a exploração e alienação, mas ignoram a contribuição das análises feministas sobre trabalho doméstico. Maud Simonet (travail gratuit: la nouvelle exploitation) analisa que há 40 anos, as feministas já faziam todas as perguntas que poderiam ser feitas sobre o trabalho gratuito: qual é o valor do trabalho gratuito? Por que e como medilo? Quem se beneficia? As pensadoras feministas debatiam as questões e, já naquela época, não havia consenso nas respostas. Mas é precisamente por meio de seus debates e controvérsias que

\footnotetext{
${ }^{4}$ Capitalismo será aqui entendido como um modo de produção que visa ao lucro e à acumulação das riquezas, baseado na propriedade privada dos meios de produção e na exploração do trabalho contraditoriamente livre/subordinado.

${ }^{5}$ Patriarcado será aqui entendido como a estrutura de opressão ao gênero feminino a partir do qual se ergue o machismo e os modos pelos quais os homens assumem os papéis de liderança, autoridade, privilégio e controle, enquanto as mulheres são relegadas a trabalhos desvalorizados pelo sistema capitalista, à subserviência, à invisibilização e outras violações à dignidade a fim de mater-se a condição patriarcal.

${ }^{6}$ Cf. PNUD; IPEA. Plataforma Agenda 2030. Disponível em: http://www.agenda2030.com.br/. Acesso em: 21 mar. 2021.
} 
surgiram as reflexões e o arcabouço teórico que nos permite discutir hoje, o trabalho gratuito, inclusive o do meio digital, mas também o trabalho voluntário, o trabalho dentro de casa, os estágios curriculares obrigatórios, o trabalho de cuidados.

Nesta perspectiva, entre o "velho" mundo e o mundo atual, um elemento antes obscurecido passou a ter vital relevância para a sobrevivência da comunidade integrada, da humanidade global: profissionais da saúde e do cuidado, que instrumentalizam a cura em momentos de vulnerabilidade e viabilizam a reprodução social e que, talvez agora, estejam sendo observados com um pouco mais de atenção.

São trabalhadoras/es que estão contidos na rotina do dia a dia e dos quais muitos, senão todos, necessitarão em algum momento da vida, seja para acompanhar algum familiar em acidentes, doenças, cirurgias ou ainda, simples exames ou cuidados cotidianos. São esses trabalhadores e trabalhadoras que estarão presentes com a atenção no desenvolver do procedimento, na prescrição de medicamentos, no cuidado com a alimentação, no apoio psicológico, na higiene e ao longo de todo desenvolvimento do ser humano, na medida que necessita de cuidados.

Apesar da fundamentalidade indaga-se: as atividades e condições de trabalho eram vistas socialmente e as reivindicações reconhecidas como legítimas por parte da população, dos órgãos regulamentadores, das autoridades legislativas? A invisibilidade dessas atividades, na maioria das vezes vinculada às mulheres, está verdadeiramente superada?

Esses problemas e perguntas constituem o norte do trabalho que tem como objetivo principal promover uma reflexão crítica sobre os sustentáculos estruturais e institucionais das opressões que incidem diretamente sobre as pessoas que se dedicam ao cuidado.

$\mathrm{O}$ artigo se valeu da análise qualitativa de textos acadêmicos que debatem sobre o trabalho de cuidados, além de notícias e casos do judiciário que possibilitaram detectar o machismo incrustado na sociedade e no direito. Em função da existência de reclamações trabalhistas e decisões analisando a relação de emprego no trabalho de cuidados, buscou-se decisões de segundo grau de casos concretos no judiciário brasileiro, via plataformas de busca de jurisprudência trabalhista, utilizando-se como palavras de busca as que gravitam no campo lexical de: "trabalho doméstico", "trabalho de cuidado", "relação de emprego", "relação de família", a exemplo das palavras “cuidadora", “empregada doméstica", “irmã”, “mãe”, "sogra”, entre outros termos assemelhados que permitissem verificar como a jurisprudência reflete a naturalização do papel de cuidadora atribuído às mulheres. Entretanto, a pesquisa quantitativa ainda está em andamento e o presente texto foi elaborado com base na fundamentação teórica 
utilizada pela maioria das decisões pesquisadas. O trabalho não traz, portanto, análise das decisões brasileiras, mas análise da fundamentação usada pela maioria pesquisada até o momento.

O texto se divide em 7 seções que objetivam discutir as especificidades do problema. A primeira diz respeito a uma contextualização inicial dos trabalhos ligados aos cuidados na atualidade a partir de duas situações de tensionamento do tecido social. Depois é abordada a divisão sexual do trabalho e como ocorre a naturalização dessa opressão. Seguindo para a análise de como ocorre a desvalorização do trabalho de cuidado enquanto profissão e os motivos por trás desses fenômenos, evidenciam-se os elementos relacionados à raça e que são trazidos para o debate sobre a feminização do trabalho e violência institucionalizada, retomando as situações descritas na contextualização. Por fim, discorre-se sobre como o direito confere suporte jurídico a essas opressões, precisando ser reformulado a partir de um diálogo com a teoria feminista.

\section{A OBSCURIDADE DO VELHO MUNDO: CONTEXTUALIZANDO O CENÁRIO}

Para alcançar o objetivo do presente texto faz-se necessário realizar uma contextualização a partir de duas situações concretas em que o velho patriarcado, obscuro e atrasado, é exposto à sociedade num momento crítico.

O primeiro foi muito noticiado, Miguel Otávio Santana da Silva, de 5 anos, de família pobre, filho de uma mulher negra e empregada doméstica, morreu ao cair do $9^{\circ}$ andar de uma das luxuosas torres construídas no Cais de Santa Rita, no bairro de São José, no Recife. Tendo em vista as circunstâncias em que a tragédia aconteceu, a morte torna-se um símbolo da desigualdade social no Brasil.

A mãe da criança, Mirtes Renata Souza, estava trabalhando como empregada doméstica, mesmo em meio à pandemia do novo coronavírus. Miguel, por outro lado, estava sem aulas na rede pública de ensino devido a pandemia do COVID-19 e há alguns dias não via sua mãe. Pediu para acompanhá-la no trabalho, pois sentia sua falta. A tragédia aconteceu enquanto sua mãe passeava com os cães dos patrões Sari Corte Real e Sérgio Hacker (à época prefeito do município de Tamandaré/PE pelo PSB), deixando o filho aos cuidados da patroa e de uma manicure que estava no apartamento. Vídeos das câmeras de segurança mostram que a patroa acompanhava as idas de Miguel ao elevador, e, por fim, deixou-o sozinho. A criança na tentativa 
de encontrar sua mãe, desceu do elevador num andar sem proteção, escalou um pequeno gradil e caiu em seguida.

Segundo a polícia, a criança morreu ao cair do prédio porque foi procurar pela sua mãe. A própria mãe foi socorrer o filho após a queda, junto com médico, morador do edifício, levando-o para o hospital. Infelizmente, ele não sobreviveu. A Patroa foi presa sob suspeita de homicídio culposo e, logo em seguida, foi solta por pagar fiança de 20 mil reais para responder em liberdade.

O segundo exemplo a ser apresentado neste texto ocorre no mesmo ano da tragédia apresentada anteriormente. Os tempos que antecederam os atuais, proporcionados pelo rompimento da Covid-19 com a barreira do estado normal, que hoje se materializa em isolamento social, estado de emergência em saúde pública, podem ser denominados de "tempo de normalidade institucional e política”, embora no auge da crise do sistema democrático liberal. Este será o tempo que nos representará nesta parte da escrita, os vividos no velho mundo.

Em 30 de janeiro de 2020, a classe de técnicos de enfermagem, que trabalhavam nos maiores hospitais públicos do Estado de Pernambuco - Brasil, fez greve por melhores condições de trabalho e salário. Dentre os pedidos estavam a isonomia salarial (a categoria tem três faixas de remuneração) e salário-base de $\mathrm{R} \$ 774,00$, valor abaixo do salário-mínimo, adicional noturno, adicional de insalubridade e atualização do Plano de Cargos, Carreiras e Vencimentos (PCCV).

Após 12 dias de greve, fizeram uma forte manifestação de 12 horas consecutivas que foi duramente reprimida com gás de pimenta pela polícia militar do estado, sob a liderança do governador Paulo Câmara do Partido Socialista Brasileiro (PSB). A ação policial culminou com a detenção do presidente do Sindicato Profissional dos Auxiliares e Técnicos de Enfermagem de Pernambuco (SATENPE) que responderá judicialmente pelo suposto crime de desobediência.

Apesar da paralização, todos os serviços hospitalares foram mantidos por meio de revezamento entre os profissionais, afirmaram os atores envolvidos. O movimento foi considerado ilegal pelo Tribunal de Justiça de Pernambuco, que entende ser impossível a realização de greve no serviço público, dentre outros motivos.

A manifestação por melhorias de condições de trabalho não é exclusividade do manifesto promovido em 2020. Em novembro de 2019, por exemplo, houve denúncia de falta de ar condicionado em outro hospital público escolar, Hospital Oswaldo Cruz, na região 
metropolitana da capital pernambucana, o que deixava o ambiente de trabalho insalubre, numa temperatura média de 28 graus.

Por décadas, profissionais de saúde pública, no caso das auxiliares e técnicas de enfermagem, sofrem com baixos salários que são, em média, equivalentes ao salário mínimo nacional. Já no caso da classe médica, pouco menos de um salário mínimo por plantão de 12 horas realizado.

Os casos são exemplares na representação de um eixo central do texto: os ofícios relacionados ao care (cuidados), são representados, na sua maior parte, por atividades realizadas por mulheres, trabalhadoras domésticas, profissionais de saúde, professoras do ensino escolar, assistentes sociais, que representam também, na sociedade brasileira, trabalhadoras que executam atividades pouco ou não remuneradas, com os menores salários e a menor atenção da sociedade e da mídia.

Os trabalhos ligados aos cuidados são desgastantes, extremamente exaustivos e de elevada importância nos espaços de aprendizagem e educação, além de serem essenciais às equipes de profissionais de saúde e indispensáveis para os cuidados diários necessários à reprodução social.

Mas como se verá, por serem atividades atribuídas às mulheres, por serem naturalizadas dessa forma, e pelo fato de as mulheres (junto com o trabalho que desempenham) serem menosprezadas na sociedade do velho patriarcado, as atividades a elas atribuídas não são valorizadas, são desqualificadas e, quando possível, sequer vistas como trabalho, i.e. invisibilizadas.

\section{TRABALHO E GÊNERO.}

Conectar-se com todas as questões que estão circunscritas pelo contexto da pandemia é observar aspectos que há muito estão latentes no nosso contexto social, mas que só agora parecem ganhar corpo.

Kylie Jarret (2015) denuncia vigorosamente que as pesquisas e análises das "novas" formas gratuitas de trabalho surgidas a partir da era digital, seriam novas formas de exploração fundadas nas emoções daqueles/as que vivem do trabalhado porquê "Sim, claro, quando isso interessa aos homens brancos, heterossexuais, cis, de classe média ou de classe alta, isso pode parecer novo. Para todos os outros, é o que acontece há tempos”. 
É possível perceber que a partir dos anos 90 houve a expansão dos trabalhos de cuidados, isto é, o aumento da mercantilização e da externalização de um trabalho tradicionalmente alocado às mulheres. Aquele trabalho tradicionalmente gratuito e realizado "por amor": o cuidado da casa, das crianças, dos idosos, dos doentes e restritos à esfera dita "privada", no seio da família. E que, desde o início do século XXI, a chegada de uma crise econômica e a reprodução e aprofundamento das desigualdades sociais resultam na retomada das análises do papel do trabalho na construção e manutenção da sociedade patriarcal e no arranjo sexuado do mercado de trabalho.

A crise sanitária vivenciada apresenta a oportunidade de finalmente se voltar à atenção para o tema; e ele ser explorado, questionado e debatido. Agora, mais do que nunca se deve compreender, aprofundar e problematizar a concepção que já fora apresentada por Elisabeth Souza- Lobo: "A classe operária tem dois sexos".

Aqui vale acrescentar que não é possível se evadir de um tema que se relaciona diretamente com o aumento da inserção da mulher no mercado de trabalho. Sabe-se que a divisão sexual do trabalho incide sobre mulheres e homens, pois ela determina papéis a esses dois universos, feminino e masculino, fundamentando hierarquias de gênero, restrições e delimitações de funções sociais. Mas não é apenas isso, está claro, através de pesquisas e do que está visualmente expressado na sociedade, que mulheres negras, no Brasil, são o maior número de mulheres empregadas em trabalhos precários (FONTOURA et al 2017). Dessa forma torna-se imprescindível acrescentar a todas essas questões apresentadas o debate que envolve raça.

Percebe-se que a divisão sexual de trabalho abrange uma conjunção de gênero, classe e raça e que todos esses fatores serão refletidos na alocação, ascensão e remuneração das mulheres no mundo do trabalho. E embora se reconheça que existe um aumento da participação das mulheres no trabalho assalariado, que representa uma fissura na tradicional dependência econômica dessas, os dados parecem apontar que não se superou o cenário de subordinação e de sujeição delas, principalmente das mulheres negras, como Mirtes, a mãe de Miguel.

É preciso atenção pois a absorção cada vez maior da força de trabalho feminina feminização ${ }^{7}$ do trabalho - não é necessariamente o aperfeiçoamento da igualdade e uma melhor reconfiguração da divisão sexual do trabalho. Os empregos criados são, entretanto, marcados

\footnotetext{
${ }^{7}$ Expressão extraída do trabalho de Claudia Mazzei Nogueira intitulado "A feminização no mundo do trabalho: entre a emancipação e a precarização".
} 
pela vulnerabilidade e a precariedade, as modificações tecnológicas produzem efeitos complexos, contraditórios e é inegável que essas transformações e o isolamento vivenciado no contexto da pandemia levam a consequências de aprofundamento das desiguais sobre o emprego masculino e feminino.

As mulheres, tradicionalmente responsáveis pelo trabalho doméstico e outras responsabilidades familiares estão mais sujeitas ao tipo de vínculo mais precário. Como se percebe a lógica da divisão sexual do trabalho, no contexto de uma sociedade, da família patriarcal, é transplantada para o mundo assalariado e tende a ratificar a ideia histórica e socialmente repetida de que o trabalho feminino tem um menor valor. Apresenta em si prioritariamente especificidades afetivas que são da "natureza" feminina.

Essa situação se traduz em uma acentuada exploração feminina no mundo do trabalho, a sofisticação da opressão masculina sobre a mulher no espaço privado/da reprodução é base para pressão masculina que presenciamos no cerne da família patriarcal. A divisão sexual do trabalho permeia as relações sociais e é fundamental na sua estruturação.

Essa construção que implica na desvalorização das atividades atribuídas às mulheres quando comparada às dos homens é o reflexo de uma sociedade inserida em uma estrutura de poder hierarquizada existente nas relações patriarcais. O patriarcado, como sistema político, consiste numa estrutura de exploração que tem como núcleo a divisão sexual do trabalho retratada na exploração do trabalho das mulheres.

Logo, percebe-se a importância de compreender e reconhecer que há uma interdependência e uma imbricação das relações sociais de poder e gênero, de raça e de classe social que confere uma grande complexidade e envergadura aos estudos de gênero e trabalho na atualidade.

A crise atual, que não é apenas sanitária, fez-nos viver algo novo. Fez ressurgir antigos problemas e resgatar a necessidade de uma reconstrução da realidade. O primeiro passo talvez seja reconhecer que o gênero está no centro das relações de trabalho.

Mas conforme destaca Boaventura de Sousa Santos (2020), qualquer situação de pandemia é discriminatória, logo, mais difícil para certos grupos sociais do que para outros. A tragédia que acontece no meio da maior crise de saúde do século abre lugar para discussões a respeito de racismo, divisão sexual do trabalho, a institucionalização da opressão e a desvalorização de certos tipos de trabalho.

Partindo dos debates feministas sobre o trabalho doméstico, podemos concluir três perspectivas para analisar essas formas cívicas e digitais de trabalho gratuito. 


\begin{abstract}
A primeira lição é que o trabalho gratuito não deve ser pensado como uma subtração - trabalho menos remuneração - mas como uma negação do trabalho, um não reconhecimento do trabalhador como trabalhador e, em nome de determinados valores: em nome do amor (não é trabalho, é amor!), em nome da "cidadania", mas também em nome da "paixão" pelo trabalho gratuito na internet. A segunda lição dessas análises feministas do trabalho doméstico é convidar-nos a nos afastarmos do mercado para pensar sobre a exploração, mostrando que ela é realizada e também se operacionaliza em "nossas cozinhas e em nossos quartos". Para citar Silvia Federici e Nicole $\mathrm{Cox}^{8}$, também em nossos chamados espaços de "lazer" ou "engajamento". Finalmente, por meio de vários debates, entre feministas marxistas e materialistas sobre a relação entre capitalismo e patriarcado, pelo feminismo negro sobre a pluralidade das relações sociais de sexo, classe e raça, as análises feministas do trabalho doméstico, de alguma forma, forçaram-nos a pensar sobre a pluralidade de formas de exploração das mulheres e a des-homogeneizar suas experiências. Elas colocam as relações sociais no centro da análise do trabalho. (Entrevista realizada pelo DIGILABOR, 2020, com a autora Maud Simonet sobre o recente livro em co-autoria com Silvia Federici - Travail gratuit et grèves féministes -, lançado em novembro/2020 ainda não disponível ao público brasileiro)
\end{abstract}

Além dessas três importantes lições, quanto à desfiguração do trabalho feminino enquanto tal, à necessidade de refletir sobre a exploração nas diversas vivências do feminino e analisar como ela se estrutura em relação com a pluralidade heterogênea de formas de exploração de mulheres, no texto apontado de Federici e Cox (1975) existe ainda uma proposta de pressão que se pode exercer a partir do salário.

The family, in fact, is essentially the institutionalization of our wageless labour, of our wageless dependence on men, and consequently, the institutionalization of a division of power which has successfully functioned in disciplining us and the men as well. For our wagelessness, our dependence in the home, has functioned to keep the men tied to their jobs, by ensuring that whenever they wanted to refuse their work they would be faced with the wife and children who depended on their wage. (Cox et Federici, 1975. p.7)

As autoras vão dizer que o capital usa o salário para dividir a classe, atribuindo salários diferentes para jovens, negros, mulheres e homens brancos, opondo inclusive a classe trabalhadora, que recebe salário e paga impostos, a uma de desempregados que usufruem de um bem-estar "sem pagar por isso", refletindo, inclusive, nas relações domésticas de dependência, em que as mulheres são vistas como "o infindável buraco" do contracheque do marido.

\footnotetext{
${ }^{8}$ Cf. COX, Nicole; FEDERICI, Silvia. Counter-planning from the kitchen: wages for housework a perspective on capital and the left. New York: New York Wages for Housework Committee, 1975. Disponível em: https://caringlabor.files.wordpress.com/2010/10/counter-planning_from_the_kitchen.pdf. Acesso em: 10 mar. 2021.
} 
Por outro lado, asseveram que quando a correspondência entre a produção e a remuneração é pautada, em especial quando se fala em trabalho doméstico, o próprio capitalismo é posto em cheque. Isso significa que o capital tem que pagar pela enorme quantidade de serviços domésticos que hoje extraem a custo zero. Essa postura se trata, portanto, de uma recusa em aceitar o trabalho atribuído às mulheres como um destino biológico, feito por “amor", para enxergá-lo enquanto tal, enquanto trabalho propriamente dito.

\section{A DESVALORIZAÇÃO DE UM TRABALHO: O CUIDADO COMO PROFISSÃO.}

Nas sociedades capitalistas a maior parte dos ofícios relacionados ao care, assim como o papel da reprodução social são encobertos e renegados. Muitas vezes, diante da invisibilidade dada a essas profissões não se percebe a sua essencialidade para a existência e sustentação das sociedades e das famílias.

Vale destacar que para Hirata e Kergoat (2007) é possível definir o trabalho do care sob duas perspectivas: podemos entendê-lo como um conjunto de atividades materiais, técnicas e relacionais que consistem em apresentar uma resposta concreta às necessidades dos outros. $\mathrm{E}$, também, como uma relação de serviço de apoio e assistência que implica a responsabilidade com relação à vida e ao bem-estar de outrem. Essas atividades são desenvolvidas em maior número por mulheres, majoritariamente mais pobres, menos qualificadas e classes subalternas.

A categoria de pessoas que trabalham com cuidados tem muito a dizer sobre as relações de desigualdade existentes na nossa sociedade, em especial as pessoas que trabalham com cuidados, função classicamente feminina e desvalorizada, alvo de desigualdade social.

Esse padrão é herança da estruturação patriarcal e hierárquica do período escravocrata, em que cabia às escravas a realização das obrigações domésticas e o cuidado com a prole das “sinhás". Afinal, o Trabalho Doméstico teve seu marco histórico no período colonial; a atividade doméstica era desempenhada por mulheres negras, escravas, que assumiam funções de amas de leite, mucamas, costureiras, aias, cozinheiras, babás, sofrendo explorações das mais diversas.

As intersecções entre raça, classe e gênero atravessam a vida cotidiana. O constrangimento e a ameaça, que colocam as trabalhadoras domésticas em risco para que continuem a servir seus patrões mesmo diante de uma pandemia, não são novidades da burguesia, mas heranças de uma branquitude colonialista brasileira. Aprofundadas nas 
sociedades capitalistas (que) sempre instituíram uma divisão racial do trabalho reprodutivo. Quer por meio da escravidão e do colonialismo, que pelo apartheid ou pelo neoimperalismo, esse sistema forçou mulheres racializadas a fornecer esse de graça- ou a um custo muito baixo- para suas "irmãs" de etnicidade majoritária ou brancas (ARRUZZA, BHATTACHARYA, FRASER, 2019, p. 51).

O Estado de Pernambuco instituiu o lockdown entre os dias 16 e 31 de maio/2020, mas empregadas domésticas e cuidadoras que trabalhassem em residências cujos empregadores exercessem atividades essenciais ou integrassem grupo de risco foram excluídas da quarentena.

Angela Davis elucida a desvalorização do trabalho doméstico a partir da consolidação do capitalismo e da Revolução Industrial, quando toda a economia se desloca para longe do ambiente privado. A mercadoria produzida nas fábricas, diferentemente das tarefas domésticas, satisfaz a demanda de lucro do empregador, a partir disso, "o trabalho doméstico foi naturalmente definido como uma forma inferior de trabalho, em comparação com a atividade assalariada capitalista” (DAVIS, 2016, p. 230).

Para além disso, o próprio conceito de profissão desenvolvido pela sociedade classista requer atributos exclusivos, conhecimentos científicos e técnicos, obtidos após uma longa formação. Partindo dessa concepção, o trabalho realizado dentro das nossas casas é visto como natural, como uma ocupação e não profissão, o que limita seu valor econômico e desqualifica esse trabalho.

Como consequência desses aspectos, a profissão teve seus direitos consolidados muito tardiamente e de forma ainda muito precária, com salários instituídos na base do mínimo, e ainda assim na informalidade.

Sobre essa forma de precarização laboral a partir da jornada diferenciada das trabalhadoras no âmbito doméstico, Cláudia Nogueira (2014) acrescenta que, a modalidade de degradação dos direitos está reservada para a mulher trabalhadora, porque o capital, além de reduzir ao limite o salário feminino, também necessita do tempo de trabalho das mulheres na esfera reprodutiva, que é imprescindível para o processo de valorização do capital, uma vez que seria impossível o capital realizar o ciclo produtivo sem o trabalho feminino na esfera reprodutiva.

\section{A DIVISÃO SEXUAL E RACIAL DO TRABALHO E A INSTITUCIONALIZAÇÃO DA OPRESSÃO.}


A divisão sexual do trabalho é um termo usado para se referir à diferenciação de tarefas responsabilidades entre homens ou mulheres por razão exclusiva de seu sexo biológico, que é não apenas decorrente das relações sociais entre os sexos, mas da forma de reprodução social. Nesse sentido, são historicamente reproduzidas situações que destinam homens à esfera de trabalho produtiva - consequentemente a funções com maior valor social agregado - e mulheres à esfera reprodutiva, intrinsecamente ligada ao trabalho doméstico (HIRATA; KERGOAT, 2007).

Por isso, o trabalho de cuidado ainda é majoritariamente considerado à atribuição feminina, e por causa da divisão sexual do trabalho as mulheres ainda lutam em dobro para conquistar seu lugar no mundo do trabalho produtivo. E ainda que nas últimas décadas tenha havido uma crescente inserção das mulheres no mercado de trabalho, isso não significou uma modificação nas relações de trabalho doméstico e/ou de cuidados (ÁVILA; FERREIRA, 2014).

Nessa divisão sexual do trabalho é possível fazer um segundo recorte, que é a divisão racial do trabalho. As mulheres pretas e pardas ainda são as mais vitimadas pelas desigualdades propagadas na sociedade. A partir de dados da Pesquisa Nacional de Amostra de Domicílios Contínua (PNAD Contínua), o Ipea constatou que o trabalho doméstico é expressivamente ocupado por mulheres negras, de baixa escolaridade e de famílias pobres. E mais, empregadas domésticas brancas têm salários maiores que as negras em todas as regiões do Brasil (PINHEIRO et al, 2019).

Uma violência institucionalizada significa que as opressões sofridas por aquele grupo ou grupos de pessoas podem ocorrer em qualquer instância da sociedade, desde órgãos públicos até instituições de ensino, empresariais privadas e públicas etc. O problema é que quanto mais institucionalizada uma opressão, mais ela se naturaliza na sociedade. Um exemplo disso é como o genocídio da população negra torna-se apenas estatística no imaginário popular, sem capacidade de chocar ou revoltar a população. Ou o trabalho domiciliar de cuidados familiares traduzidos como amor incondicional e sem necessidade de quaisquer retribuições financeiras.

A sintomática tragédia do menino Miguel aconteceu durante a onda de protestos antirracistas que ecoa nos Estados Unidos, diante da violência policial que assassinou George Floyd. E, no mesmo momento em que ecoam os gritos de "vidas negras importam", no dia 3 de junho de 2020, o mesmo da morte de Miguel, o vice-presidente Hamilton Mourão publicou um texto em que afirma não existir racismo no Brasil e ainda intitula os protestos pela democracia e antirracistas como "baderna". O timing não poderia ser mais preciso para denotar a crise de humanidade que vivemos. 
Afinal, o caso Miguel e as paralizações dos trabalhadores da saúde no mês imediatamente anterior ao da decretação da pandemia expõem as estruturas patriarcais impostas pela lógica escravista e capitalista na sociedade brasileira, e o porquê da banalização do sofrimento de vidas majoritariamente vividas por mulheres negras e pobres, e o porquê de um menino de apenas 5 anos não ter sido digno de cuidados de uma adulta branca que estava responsável por ele naquele momento. Em carta aberta, Mirtes, mãe de Miguel, escreveu que perdeu o sentido da vida sem Miguel: "Uma mãe, sem seu filho, sofre uma crise, não apenas de identidade, como também de existência. Quem sou eu sem Miguel? Ela tirou de mim o meu neguinho, minha vida, por quem eu trabalhava e acordava todos os dias".

Nessa conjuntura, e por causa dessa forma como a sociedade ainda lida com o trabalho de cuidados domésticos, foi que Miguel perdeu sua vida. Um menino que, com saudades da mãe, foi junto com ela para o lar onde ela trabalhava; que, invisibilizado pela sua cor, pela sua classe, e pelo fardo que carrega pelo estigma social, não foi relevante o suficiente para ter sua vida cuidada; que saiu sozinho vagando por um edifício, por desatenção, descuido ou descaso da patroa, até cair do $9^{\circ}$ andar.

O acidente que ocasionou a morte de Miguel demonstra a internalização de uma cultura colonial e patriarcal institucionalizadas. Mirtes, preta, empregada doméstica, sai de sua casa mesmo durante a quarentena, para cuidar da casa dos outros, brancos, enquanto não há quem cuide da sua. Realidade de milhões de mulheres no Brasil, invisibilizadas pela sua origem, cor e classe social.

Por fim ainda, cabe a reflexão sobre a alienação da vida das empregadas domésticas, suas condições de trabalho e como a sociedade ainda enxerga esse ofício, reproduzindo as mesmas estruturas.

\section{OS TRABALHOS DE CUIDADOS DOMÉSTICOS NO DIREITO: A SUSTENTAÇÃO JURÍDICA DO PATRIARCADO ATRAVÉS DA INVISIBILIZAÇÃO E NATURALIZAÇÃO.}

Como visto até aqui, a desvalorização do trabalho ligado aos cuidados e a sua atribuição a mulheres, em especial mulheres negras, são fatos presentes na sociedade capitalista, que se estrutura sobre os pilares das opressões de classe, raça e gênero. Como o direito, em especial o direito do trabalho e seu sistema de justiça, lida com esta situação é sobre o que se propõe refletir agora. 
O direito brasileiro garantiu uma condição menos favorável que a de qualquer outra categoria ao trabalho doméstico na disciplina do trabalho remunerado.

Apesar de alguns poucos avanços e muitos retrocessos a cada inovação legislativa, as pessoas que trabalham com cuidados domésticos no Brasil ainda tem, quando reconhecido esse trabalho enquanto tal, significativamente menos direitos que as demais categorias de trabalhadores, algo assegurado constitucionalmente pelo parágrafo único do art. $7^{\circ}$ da CRFB.

Uma situação diferente que se observa, por outro lado, dá-sena interpretação da legislação. Nesse momento, da interpretação, encontra-se um importante componente da invisibilização do trabalho doméstico e da naturalização da atribuição desse trabalho às mulheres. Na definição de se um fato juridicamente relevante atrai ou não a incidência das normas protetivas do trabalho doméstico, compelindo o demandado a remunerar o que antes estava invisível, evidenciados os requisitos jurídicos para configuração da relação de emprego doméstico.

Quando se observa a jurisprudência e a doutrina brasileiras, a naturalização do papel atribuído às mulheres se mostra ainda mais evidente. Nicoli e Pereira (2020), ao realizarem uma crítica dissidente do direito do trabalho, exemplificam na doutrina do manual de Maurício Godinho Delgado, que traz como motivação para o seu posicionamento, para além de outras questões ligadas à existência ou não de certos requisitos da relação em emprego em uma relação conjugal, que, no âmbito familiar em geral, o "ânimo benevolente do trabalho prestado pode também descaracterizar a relação empregatícia doméstica" (DELGADO, 2019, p. 445). Com isso, o doutrinador faz tabula rasa da cultura patriarcal que atribui esse trabalho como natural a determinadas pessoas da família, frequentemente mulheres, contribuindo para naturalização e invisibilização dessa relação laboral, com suporte de uma hermenêutica jurídica que aqui se problematiza.

Em outra exemplificação os autores trazem um caso de uma irmã cuidadora que não teve o vínculo de emprego doméstico reconhecido por ser considerada "situação comum" a pessoa idosa ser "acolhida e amparada por familiares (irmãos) sem o intuito de relação de emprego". Em grau recursal, o entendimento que restou sedimentado foi de que: "prevalece (...) a presunção de que a ajuda prestada ao irmão decorreu da relação de parentesco existente entre as partes, de caráter afetivo e colaborativo".

Essa mesma constatação pode ser realizada analisando a interpretação utilizada por diversos tribunais espalhados pelo Brasil. Através de análise de decisões realizada nas plataformas virtuais de busca de jurisprudência trabalhista, pode-se constatar como a 
interpretação do direito tem caminhado majoritariamente no sentido de negar contraprestação às atividades de cuidado realizadas por mulheres. Embora a pesquisa quantitativa ainda esteja em andamento, é possível analisar os fundamentos utilizados pela maioria já pesquisada e evidenciar algumas.

Nos fundamentos para resolução do caso 0011172-97.2015.5.03.0132 do TRT-3 entendeu-se que o "fato de a reclamante realizar tarefas do lar não significa, necessariamente, que era empregada doméstica". E prosseguiu afirmando que, na realidade, "a autora passou a integrar aquela família, desempenhando tarefas que qualquer ente familiar realizaria, como a limpeza da casa e cuidados com um parente idoso, como é o caso[...]” (BRASIL, 2017a).

Nesse caso, a onerosidade, inclusive, foi rechaçada e o dinheiro recebido pelo serviço, visto como "mesada" e não "salário".

Em outro caso do Judiciário Mineiro, 0010215-39.2016.5.03.0075, o entendimento partiu da ideia de que não haveria intenção de contratar (requisito questionável) entre uma sogra e um genro. Mais interessante foi a argumentação da defesa, que tentou induzir que uma relação de cuidado prévia já naturalizada, embora remunerada, contaminava uma relação que passou a existir fora do ambiente doméstico do seio familiar. A defesa teria dito que a sogra se ofereceu para cuidar dos netos do demandado enquanto os pais estivessem trabalhando, ocasião na qual a filha, esposa do réu, ofereceu uma ajuda de custo de $\mathrm{R} \$ 500,00$. Após isso, a sogra chegou a ajudar na empresa do genro devido ao acréscimo de movimento e a genro pagou $\mathrm{R} \$ 200,00$ num determinado dia e disse que o pagamento continuaria se a sogra o ajudasse nos dias com muito movimento (BRASIL, 2017b). O cerne da tese da defesa foi a de que a ajuda familiar não caracterizaria o vínculo, e assim, do lar à empresa, não se reconheceu qualquer relação jurídica trabalhista, consolidando-se a tese de que o trabalho foi realizado em "ajuda mútua" entre membros do núcleo familiar.

Situação semelhante ocorreu no TRT-7, no processo 0000002-12.2018.5.07.0036, quando uma relação de emprego também foi contaminada pela relação familiar, naturalizandose o trabalho doméstico feminino de maneira lateral na fundamentação. Nessa situação, como na anterior, a mulher não teve vínculo de um emprego externo ao ambiente domiciliar reconhecido em função da relação familiar, por ser companheira do demandado, algo comprovado, dentre outros fatores, pelo fato de ela realizar as tarefas domésticas (BRASIL, 2018a). Logo, em uma decisão só, não apenas o trabalho efetivamente realizado no lar e não remunerado é invisibilizado - como se não fosse trabalho -, e naturalizado como dever da 
mulher da família, em uma relação puramente familiar, mas também qualquer trabalho exercido por ela e para ele fora do lar é contaminado é considerado relação familiar.

No caso 0010042-82.2016.5.03.0182, após o falecimento da senhora com quem residiu durante mais de 43 anos, uma mulher ajuizou ação trabalhista contra o espólio, pedindo o reconhecimento do vínculo de emprego como doméstica. Mais uma vez foi utilizado o argumento da relação familiar para desfigurar o vínculo trabalhista, apontando-se que o filho da reclamante também morava na casa e se referia à idosa falecida como "mãe". Considerouse que a simples realização de tarefas domésticas pela reclamante não demonstra subordinação jurídica, até porque, “o esperado é que os serviços domésticos sejam realizados por todos os moradores da residência" (BRASIL, 2017c). Mas se ao menos o que é "esperado" pelo magistrado fosse uma situação comum na sociedade brasileira, talvez a problemática abordada no presente texto fosse sensivelmente menor.

Em Pernambuco, o 0001102-95.2018.5.06.0014 seguiu a mesma linha de raciocínio quando uma sogra processou a "ex-nora" por ter se encarregado do cuidado dos netos. Como na maioria dos casos, entendeu-se que "existia, em verdade, uma mútua colaboração entre as partes, pautada pelo respeito, pela confiança e pelo afeto, como deve ser em toda família" (BRASIL, 2020).

Em outro processo do TRT-6, o caso 0000467-40.2017.5.06.0341, a relação de emprego entre a sobrinha e um "filho adotivo" - também sobrinho - da tia foi desfigurada sob o argumento não apenas de haver, em verdade, uma relação familiar, mas também pelo fato de morarem na mesma residência sem que o demandado lhe cobrasse aluguel, configurando a "ajuda mútua" (BRASIL, 2018b). No caso a sobrinha era quem realizava os trabalhos de cuidado da tia até o falecimento desta e após isso seguiu morando no local realizando as tarefas domésticas.

No processo 0020737-03.2016.5.04.0721 do TRT-4, mais uma vez, embora expresso na ementa que "inexista vedação legal à configuração de emprego entre familiares", consolidouse a tese segundo a qual "não havia relação subordinada, mas sim familiar", pois a "autora morava com sua mãe e na condição de filha lhe prestava auxílio" (BRASIL, 2018c).

E no TRT-22, nos autos do processo 0000641-83.2016.5.22.0003, chegou-se a dizer que até uma relação "quase familiar" (BRASIL, 2017d), de afeto entre as partes litigantes, tornaria insustentável a formação de um vínculo empregatício. 
Em muitos casos afirma-se que a mera relação de família não desfigura eventual relação de emprego, mas o apego ao fato de se tratar de uma relação familiar é o eixo central da fundamentação para negar qualquer proteção jurídica e contraprestação pelo serviço.

Há casos em que o juízo seguiu entendimento em sentido contrário, mas o que se pretendeu abordar com o presente tópico é a persistente existência de decisões espalhadas pelo Brasil que reforçam a concepção de que, na relação familiar e afetiva, quando exercida a exaustiva tarefa de cuidado, geralmente por mulheres, isso é visto como natural, comum, uma espécie de "cooperação" e, contraditoriamente, portanto, não passível de qualquer contraprestação pelo trabalho ou proteção social.

A justiça e todo o sistema jurídico que sustentam a sociedade de modo imbricado à política e à economia parece não se dar conta da extensão e profundidade dos efeitos de tal hermenêutica.

Nas palavras de Márcio Túlio Viana (2014, p.15-16), ao defender os sentidos por ele atribuídos à CLT, finalizou seu artigo com uma reflexão que aqui se propõe expandir em direção às ideias delineadas ao longo do presente trabalho:

\footnotetext{
Ainda que de forma indireta, pequena ou invisível, todos os nossos atos - julgando, inventando, protestando, legislando, trabalhando, discutindo, silenciando - irão se refletir não só no destino de tantos trabalhadores sem rosto, que não conhecemos nem iremos conhecer, mas também em nossas vidas, e nas vidas de nossos filhos.
}

Portanto, cada ato de julgamento, de silenciamento e peça legislativa que caminhou no sentido de retirar as possibilidades de emancipação social de quem labora com cuidados se protrai no tempo, consolidando um arranjo injusto de relações de poder que tende a se cronificar.

É nesse sentido que se propõe uma reflexão cautelosa acerca da aplicação, da interpretação e da própria teoria do direito, pensando não apenas em quem trabalha com cuidados no presente, mas também em quem irá cuidar no futuro. Apenas considerando as importantes contribuições das críticas feministas à teoria do conhecimento jurídico-trabalhista, a reprodução social poderá caminhar para uma efetiva solidariedade e para a cooperação real, com contribuições de trabalhadores/as de todos os gêneros, i. e. sem a imposição oculta e aviltante dos trabalhos ligados ao cuidado a um grupo social historicamente injustiçado pelo próprio direito. 


\section{CONSIDERAÇÕES FINAIS}

É inegável que vivemos um crescimento do trabalho assalariado e remunerado das mulheres, e também é possível se observar que muito já se caminhou para superar a visão homogênea da classe trabalhadora, que por muitas vezes oculta a atividade feminina, as desigualdades de gênero no mercado e serve de sustentação para a estrutura patriarcal de sociedade.

No entanto, parte das mulheres, por serem tradicionalmente responsáveis pelo trabalho doméstico e outras responsabilidades familiares, ainda estão mais sujeitas ao tipo de vínculo mais precário, vulneráveis e com acesso a salários menores que os dos homens.

A crise atual não é simplesmente uma época de sofrimento, menos ainda mero impasse na obtenção de lucro. Basta verificar os últimos dados divulgados do ranking revista Forbes ${ }^{9}$ que relata que, em meio a maior crise sanitária dos últimos tempos e a volta do Brasil ao mapa da fome, há 11 brasileiros bilionários ocupando um lugar entre os homens(!) mais ricos do mundo. O momento atual deve ser também, e fundamentalmente, de despertar político, uma oportunidade de transformação social. As relações de poder respaldadas pela interpretação judicial de que atividades domésticas revelam atitudes de amor e não relação de trabalho que deve ser remunerado precisam ser revistas, subvertidas, transformadas- sejam elas entre homens e mulheres donos do capital e dos meios de produção e os que entram com sua força de trabalho e reprodução social.

Torna-se urgente que questionamentos feministas se potencializem neste momento de crise do capitalismo. Para isso, frisa-se que o feminismo que se tem em mente não está restrito às mulheres, deve responder a uma crise do capital, sanitária e, portanto, humana, de proporções nunca imaginadas nos tempos atuais.

Há de se reconhecer uma interdependência e uma imbricação das relações sociais de poder e gênero, de raça e de classe social que confere uma grande complexidade e envergadura aos estudos de gênero e trabalho. Na atualidade, é urgente a necessidade de superação das barreiras entre "mundo" acadêmico e "mundo" institucional.

\footnotetext{
${ }^{9}$ Cf. CAMPOS, Alvaro. Benchimol e mais 10 brasileiros entram na lista de bilionários da Forbes. São Paulo: Valor. Disponível em: https://valorinveste.globo.com/mercados/internacional-ecommodities/noticia/2021/04/06/benchimol-e-mais-10-brasileiros-entram-na-lista-de-bilionarios-daforbes.ghtml. Acesso em: 07 abr. 2021.
} 
Os casos apresentados refletem parte importante da maneira de pensar do judiciário trabalhista brasileiro no tocante à invisibilização e naturalização institucional do trabalho de cuidados realizados por mulheres.

A invisibilização do trabalho deve ser analisada em conjunto com as construções e debates feministas sobre o trabalho invisível, ampliando-os e apontando como atividades específicas que antes eram realizadas no âmbito do trabalho visível derrapam em direção a formas invisíveis de trabalho.

Falar em "invisibilização do trabalho", por conseguinte, invita-nos a relacionar essas formas de trabalho gratuitos realizadas "em nome de algo" (amor, cidadania, engajamento, formação, por exemplo) e as políticas trabalhistas (dentro de casa, no mundo associativo, nos serviços públicos, nas políticas para juventudes e assistência social). Convocamos a reflexão sobre o papel do Estado e do judiciário na continuidade, na institucionalização e na utilização do trabalho gratuito, e a considerar o aspecto "cívico" - e patriarcal - da neoliberalização do trabalho.

\section{REFERÊNCIAS BIBLIOGRÁFICAS}

ARRUZZA, Cinzia; BHATTACHARYA, Tithi; FRASER, Nancy. Feminismo para os 99\%: um manifesto. Trad. Heci Regina Candiani. 1. ed.. São Paulo: Boitempo, 2019.

ÁVILA, Maria Betânia; FERREIRA, Verônica. Trabalho produtivo e reprodutivo no cotidiano das mulheres brasileiras. In. ÁVILA, Maria Betânia; FERREIRA, Verônica. Trabalho remunerado e trabalho doméstico no cotidiano das mulheres. Recife: SOS Corpo, 2014. Disponível em: https://soscorpo.org/wpcontent/uploads/livro_trabalho_versaoonline-1.pdf. Acesso em: 15 fev. 2021.

BRASIL. [Constituição (1988)]. Constituição da República Federativa do Brasil de 1988. Brasília, DF: Presidência da República, [2020]. Disponível em:

http://www.planalto.gov.br/ccivil_03/constituicao/constituicao.htm. Acesso em: 1 jan. 2021.

BRASIL. Justiça do Trabalho. Processo: RO 0000002-12.2018.5.07.0036. Relatoria: Des. Francisco José Gomes da Silva. Fortaleza. 15 jun. 2018a. Disponível em: https://pjeconsulta.trt7.jus.br/consultaprocessual/detalhe-processo/0000002-12.2018.5.07.0036/2. Acesso em: 20 fev. 2021.

BRASIL. Justiça do Trabalho. Processo: RO 0000467-40.2017.5.06.0341. Relatoria: Des. Gisane Barbosa de Araújo. Recife. 08 fev. 2018b. Disponível em: https://pjeconsulta.trt6.jus.br/consultaprocessual/detalhe-processo/0000467-40.2017.5.06.0341/2. Acesso em: 21 fev. 2021. 
BRASIL. Justiça do Trabalho. Processo: RO 0000641-83.2016.5.22.0003. Relatoria: Des. Arnaldo Boson Paes. Teresina. 19 dez. 2017d. Disponível em: https://pjeconsulta.trt4.jus.br/consultaprocessual/detalhe-processo/0000641-83.2016.5.22.0003/2. Acesso em: 21 fev. 2021.

BRASIL. Justiça do Trabalho. Processo: RO 0001102-95.2018.5.06.0014. Relatoria: Des. Gisane Barbosa de Araújo. Recife. 12 mar. 2020. Disponível em: https://pjeconsulta.trt6.jus.br/consultaprocessual/detalhe-processo/0001102-95.2018.5.06.0014/2. Acesso em: 20 fev. 2021.

BRASIL. Justiça do Trabalho. Processo: RO 0010042-82.2016.5.03.0182. Relatoria: Des. Ricardo Antônio Mohallem. Belo Horizonte. 02 mar. 2017c. Disponível em: https://pjeconsulta.trt3.jus.br/consultaprocessual/detalhe-processo/0010042-82.2016.5.03.0182. Acesso em: 20 mar. 2021.

BRASIL. Justiça do Trabalho. Processo: RO 0010215-39.2016.5.03.0075. Relatoria: Des. Sabrina de Faria Fróes Leão. Belo Horizonte. 12 mai. 2017b. Disponível em: https://pjeconsulta.trt3.jus.br/consultaprocessual/detalhe-processo/0010215-39.2016.5.03.0075/2. Acesso em: 20 mar. 2021.

BRASIL. Justiça do Trabalho. Processo: RO 0011172-97.2015.5.03.0132. Relatoria: Des. Olivia Figueiredo Pinto Coelho. Belo Horizonte. 14 dez. 2017a. Disponível em: https://pjeconsulta.trt3.jus.br/consultaprocessual/detalhe-processo/0011172-97.2015.5.03.0132/2. Acesso em: 20 fev. 2021.

BRASIL. Justiça do Trabalho. Processo: RO 0020737-03.2016.5.04.0721. Relatoria: Des. Emílio Papaléo Zin. Porto Alegre. 07 mai. 2018c. Disponível em: https://pjeconsulta.trt4.jus.br/consultaprocessual/detalhe-processo/0020737-03.2016.5.04.0721/2. Acesso em: 21 fev. 2021.

CAMPOS, Alvaro. Benchimol e mais 10 brasileiros entram na lista de bilionários da Forbes. São Paulo: Valor. Disponível em: https://valorinveste.globo.com/mercados/internacional-ecommodities/noticia/2021/04/06/benchimol-e-mais-10-brasileiros-entram-na-lista-debilionarios-da-forbes.ghtml. Acesso em: 07 abr. 2021.

COX, Nicole; FEDERICI, Silvia. Counter-planning from the kitchen: wages for housework a perspective on capital and the left. New York: New York Wages for Housework Committee, 1975. Disponível em: https://caringlabor.files.wordpress.com/2010/10/counterplanning_from_the_kitchen.pdf. Acesso em: 10 mar. 2021.

DAVIS, Angela. Mulheres, raça e classe. São Paulo: Boitempo, 2016.

DELGADO, Maurício Godinho. Curso de direito do trabalho: obra revista e atualizada conforme a lei da reforma trabalhista e inovações normativas e jurisprudenciais posteriores.18. ed.São Paulo: LTr, 2019.

DIGILABOUR. Trabalho digital e trabalho gratuito em uma perspectiva feminista: entrevista com Maud Simonet - Digilabour, 2020. Disponível em: 
https://digilabour.com.br/2020/01/11/trabalho-digital-e-trabalho-gratuito-em-umaperspectiva-feminista-entrevista-com-maud-simonet/. Acesso em: 25 mar. 2021.

FONTOURA, Natália et al. Retrato das Desigualdades de Gênero e Raça - 1995 a 2015. Brasilia: IPEA, 2017. Disponível em:

https://www.ipea.gov.br/portal/images/stories/PDFs/170306_retrato_das_desigualdades_de_g enero_raca.pdf. Acesso em: 18 mar. 2021.

FRANCISCO, Papa. Let us dream: the path to a better future. New York: Simon \& Schuster, 2020.

HIRATA, Helena; KERGOAT, Danièle. Novas configurações da divisão sexual do trabalho. Cadernos de pesquisa, v. 37, n. 132, p. 595-609, 2007. doi:

<http://dx.doi.org/10.1590/S0100-15742007000300005>. Acesso em 11 mar. 2021.

JARRETT, Kylie. Feminism, Labour and Digital Media: The Digital Housewife. Abingdon: Routledge, 2015.

NICOLI, Pedro Augusto Gravatá; PEREIRA, Flávia Souza Máximo. Os segredos epistêmicos do direito do trabalho. Revista Brasileira de Políticas Públicas, v. 10, n. 2, 2020. doi: https://doi.org/10.5102/rbpp.v10i2.6765. Acesso em: 10 mar. 2021.

NOGUEIRA, Cláudia Mazzei. Feminização no Mundo do Trabalho: Entre a Emancipação e a Precarização in: ANTUNES, Ricardo e SILVA, Maria A. Moraes (org.) O avesso do trabalho. São Paulo: Editora Expressão Popular, 2014.

PINHEIRO, Luana et al. Os Desafios do passado no trabalho doméstico do século XXI: reflexões para o caso brasileiro a partir dos dados da PNAD contínua. Brasília: IPEA, 2019. Disponível em: http://repositorio.ipea.gov.br/bitstream/11058/9538/1/td_2528.pdf. Acesso em: 20 fev. 2021.

PNUD; IPEA. Plataforma Agenda 2030. Disponível em: http://www.agenda2030.com.br/. Acesso em: 21 mar. 2021.

SANTOS, Boaventura de Sousa. A Cruel Pedagogia do Vírus. Coimbra: Almedina, 2020.

TERRANOVA, Tiziana. Free labor: Producing culture for the digital economy. Social text, v. 18, n. 2, p. 33-58, 200. doi: https://doi.org/10.1215/01642472-18-2_63-33. Acesso em: 20 mar. 2021.

VIANA, Márcio Túlio. OS SENTIDOS DA CLT. Revista da Faculdade Mineira de Direito, v. 17, n. 33, p. 194-209, 2014. doi: https://doi.org/10.5752/P.23187999.2014v17n33p194. Acesso em 20 fev. 2021 